\title{
Estimating Domestic U.S. Airline Cost of Delay based on European Model
}

\author{
Abdul Qadar Kara, John Ferguson, Karla Hoffman, Lance Sherry \\ George Mason University \\ Fairfax, VA, USA \\ akara;jfergus3;khoffman;1sherry@gmu.edu
}

\begin{abstract}
In this paper, we detail a method for calculating the cost of delays to an airline. The approach extends a EU report that calculated delays for three alternative scenarios (low cost, baseline costs and high costs) and for short delays (under 15 minutes) and long delays (over 65 minutes). Our extension to this report determines the factors that make up the multipliers presented in that report. We next apply the individual cost factor delays to US data. The approach allows one to update the cost whenever any of the factors (crew, fuel, maintenance, ground costs) change. It considers the size of the aircraft when making such calculations, both from the perspective of fuel burn and passenger costs. Our validation methodology evaluates how close our data come to that presented in their report when a conversion is made from dollars to Euros and applies 2003 cost data. Data for Philadelphia airport (PHL) is displayed as a case study to show current delay costs.
\end{abstract}

Keywords-component; airline delay costs; airline delays; economic modeling of airlines;

\section{INTRODUCTION}

The airline industry moves millions of passengers and tons of cargo annually. The Schumer report estimated that in 2007, airport delays cost about 40.7 billion dollars to the economy [1]. Disruptions in one part of the airspace impact the entire network as delays propagate. It is estimated that almost $50 \%$ of the entire airspace delays are caused by delays that originate at the New York/New Jersey/ Pennsylvania airports.

We begin this study by considering only the direct costs to the airlines of such delays. Future work will examine the network impact as well as the resulting economics costs to the various regions and other industries. In general a flight can be delayed due to several reasons, mainly:

- Mechanical problems with the aircraft.

- Schedule disruption due to bad weather or air traffic management initiatives (Ground Delay Programs (GDPs) or Air Flow Programs (AFPs)).

- Misaligned crew/ aircraft due to previous delayed flight

This research was partially funded under NASA grant NNX09AB20A.)
Weather is a major cause of delay as it reduces the capacity of both the airspace and the runways. Based on weather forecasts, air traffic management estimates the resulting reduction in capacity within various segments of the airspace and at a variety of airports. It announces Ground Delay Programs (GDPs) that hold aircraft at the departing airport, in order to have the flying aircraft better match the capacity of the system. Holding at a gate is both cheaper and safer than airborne holds, and allows the system to be better managed. Finally, the delays already described induce future delays in the system, because the aircraft or crews may not arrive at their next assignment on time. Even when the crew does arrive, they may not be able to work another flight because they have exceeded their allowable working hours.

In this paper, we focus on the final report prepared by the Performance Review Unit, Eurocontrol in 2004[2]. This EU report describes a methodology and presents results detailing the cost to airlines of delays during various segments of a trip. The costs are divided into short delays (less than 15 minute) and long delays (greater than 65). The report provides the resultant multiplier (Euros per minute) for any such segment. The types of delays considered include gate delay, access to runway delay (both taxi in and out delays), on routes delays, and landing delays (circling or longer flight paths to overcome congestion while approaching the airport). The data used in the study consisted of data collected from European airlines, air traffic management as well as interviews and surveys conducted by the research team.

This paper is organized as follows. Section II describes the EU report, Section III provides our methodology for determining the cost components and multipliers that make up the final multipliers used in the Eurocontrol report and describe our validation of the new model on European data from the period of the EU report. In Section IV, we apply our methodology to 8 weather days at Philadelphia as a case study and show the resulting delay costs for these flights. Section $\mathrm{V}$ provides conclusions and Section VI points out the future research.

\section{PERFORMANCE REVIEW UNIT REPORT (EU REPORT)}

The EU report specifies that delays incurred can be of two types: tactical delay and strategic delay. The report makes the distinction between tactical delays (delays encountered that 
are greater than the announced schedule, i.e. delays above the anticipated padding of the schedule) and strategic delays (i.e. the delay relative to an unpadded schedule). Both US and European airlines increase the arrival time over unimpeded time so that they can report "on time" performance even when the system is over-capacitated. Another distinction that the report makes is between gate-to-gate (or single flight) delays and network-level delays. The gate-to-gate delay is the delay that an individual flight incurs based on the environment it encounters, while the network delays are the effects that the flight causes to the rest of the network. The cost of delay discussed in the EU report is the tactical primary delay. In the report, two types of delays have been chosen for demonstration; delays of short duration (15 minutes or less) and delays of long duration (65 minutes or more). Similarly three cost scenarios have been used to "allow more realistic ranges of values". Table 1 shows what costs are included in these cost scenarios under different delay types. For details, see [2].

TABLE 1: LOW, BASE AND HIGH COST SCENARIOS (FROM TABLE 2-5 OF [2])

\begin{tabular}{|c|c|c|c|c|c|c|}
\hline \multirow[t]{2}{*}{ Factor } & \multicolumn{3}{|c|}{$\begin{array}{l}\text { 'short' delay type: } \\
\text { '15 minutes' basis }\end{array}$} & \multicolumn{3}{|c|}{$\begin{array}{l}\text { 'long' delay type: } \\
\text { '65 minutes' basis }\end{array}$} \\
\hline & low & base & high & low & base & high \\
\hline load factor & $50 \%$ & $70 \%$ & $90 \%$ & $50 \%$ & $70 \%$ & $90 \%$ \\
\hline transfer passengers & $15 \%$ & $25 \%$ & $35 \%$ & $15 \%$ & $25 \%$ & $35 \%$ \\
\hline arrival / departure ${ }^{(\mathrm{a})}$ & domestic & EU & non-EU & domestic & EU & non-EU \\
\hline turnaround time ${ }^{(a)}$ & 60 mins & $60 \mathrm{mins}$ & 60 mins & 60 mins & 60 mins & $60 \mathrm{mins}$ \\
\hline parking ${ }^{(g)}$ & remote & pler & pler & remote & pler & pler \\
\hline fuel price ${ }^{(c)}$ & low & base & high & low & base & high \\
\hline weight payload factor & $50 \%$ & $65 \%$ & $80 \%$ & $50 \%$ & $65 \%$ & $80 \%$ \\
\hline airborne fuel penalty ${ }^{(f)}$ & none & none & applied & none & none & applied \\
\hline hancling agent penaty & none & none & none & none & none & charged \\
\hline extra crew costs ${ }^{(d)}$ & none & none & low & none & medium & high \\
\hline airport charges & averaged & averaged & $\max / 2$ & averaged & averaged & $\max / 2$ \\
\hline $\begin{array}{l}\text { pax cost of delay to } \\
\text { AO, EUR/min }{ }^{(j)}\end{array}$ & 0 & 0 & 0.05 & 0.32 & 0.40 & 0.48 \\
\hline $\begin{array}{l}\text { aircraft depreciation, } \\
\text { rentals \& leases }\end{array}$ & \multicolumn{3}{|c|}{$\begin{array}{l}\text { Strategic cost model used: } \\
\text { please see Annex } 0\end{array}$} & \multicolumn{3}{|c|}{$\begin{array}{l}\text { Strategic cost model used: } \\
\text { please see Annex O }\end{array}$} \\
\hline BHDOC ${ }^{(0)}$ scenario & low & base & high & low & base & high \\
\hline maintenance $e^{(e)(r)}$ & $15 \%$ & $15 \%$ & $15 \%$ & $15 \%$ & $15 \%$ & $15 \%$ \\
\hline
\end{tabular}

Based on the analysis done, the EU report provides cost factors (in Euros). The delay is divided into three segments of the flight; delay on the ground at the gate (Table 2), delay while taxiing at either airport (Table 3) or delay while airborne (en-route and holding, Table 4). These segments were chosen for discussion because they reflect the fidelity of publically available data.
TABLE 2: TACTICAL GROUND DELAY COSTS: AT-GATE ONLY (WITHOUT

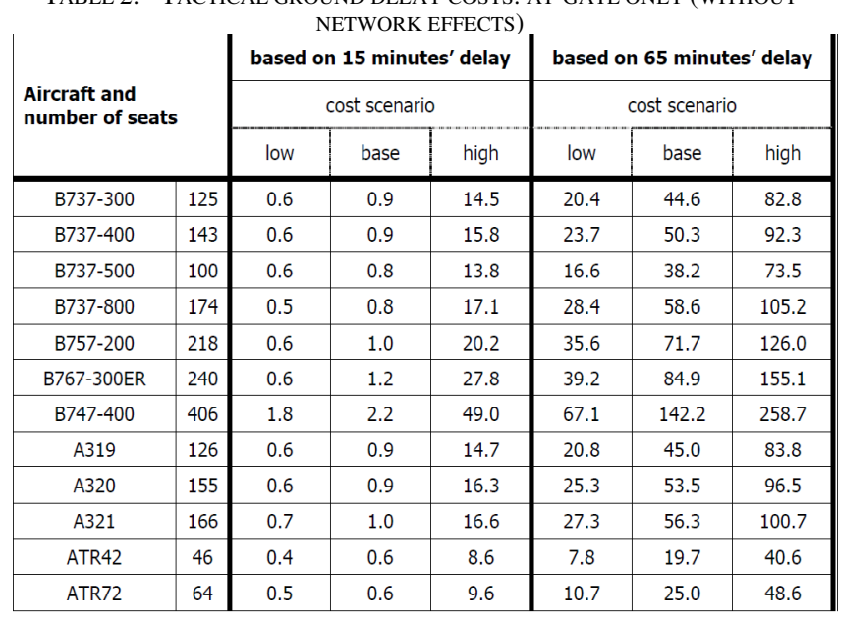

TABLE 3: TACTICAL GROUND DELAY COSTS: TAXI-ONLY (WITHOUT NETWORK EFFECTS)

\begin{tabular}{|c|c|c|c|c|c|c|c|}
\hline \multirow{3}{*}{\multicolumn{2}{|c|}{$\begin{array}{l}\text { Aircraft and } \\
\text { number of seats }\end{array}$}} & \multirow{2}{*}{\multicolumn{3}{|c|}{$\frac{\text { based on } \mathbf{1 5} \text { minutes' delay }}{\text { cost scenario }}$}} & \multirow{2}{*}{\multicolumn{3}{|c|}{$\frac{\text { based on } \mathbf{6 5} \text { minutes' delay }}{\text { cost scenario }}$}} \\
\hline & & & & & & & \\
\hline & & \multirow{2}{*}{$\frac{10 w}{3.0}$} & \multirow{2}{*}{$\frac{\text { base }}{4.6}$} & \multirow{2}{*}{$\frac{\text { high }}{19.0}$} & \multirow{2}{*}{$\frac{10 w}{22.9}$} & \multirow{2}{*}{$\frac{\text { base }}{48.4}$} & \multirow{2}{*}{$\frac{\text { high }}{87.1}$} \\
\hline B737-300 & 125 & & & & & & \\
\hline B737-400 & 143 & 3.0 & 4.7 & 20.3 & 26.1 & 54.1 & 96.6 \\
\hline B737-500 & 100 & 3.0 & 4.6 & 18.2 & 19.0 & 42.0 & 77.8 \\
\hline B $737-800$ & 174 & 2.9 & 4.5 & 21.6 & 30.8 & 62.3 & 109.5 \\
\hline B757-200 & 218 & 3.4 & 5.3 & 24.9 & 38.4 & 76.0 & 131.0 \\
\hline R767-300FR & 240 & 4.5 & 7.2 & 34.0 & 43. 2 & 91.0 & 162.1 \\
\hline$B 747-400$ & 406 & 10.6 & 15.9 & 61.7 & 76.4 & 156.3 & 276.2 \\
\hline A319 & 126 & 2.6 & 4.1 & 18.4 & 22.8 & 48.2 & 87.4 \\
\hline A320 & 155 & 2.6 & 4.0 & 20.1 & 27.3 & 56.7 & 100.1 \\
\hline A321 & 166 & 3.0 & 4.7 & 20.9 & 29.7 & 60.1 & 105.0 \\
\hline ATR42 & 46 & 0.6 & 0.9 & 8.2 & 7.9 & 20.0 & 40.0 \\
\hline ATR72 & 64 & 1.1 & 1.8 & 10.3 & 11.4 & 26.1 & 49.2 \\
\hline
\end{tabular}

TABLE 4: TACTICAL AIRBORNE DELAY COSTS AND HOLDING (WITHOUT NETWORK EFFECTS

\begin{tabular}{|c|c|c|c|c|c|c|c|}
\hline \multirow{2}{*}{\begin{tabular}{l}
\multirow{2}{*}{$\begin{array}{l}\text { Aircraft and } \\
\text { number of seats }\end{array}$} \\
\cline { 6 - 9 }
\end{tabular}} & \multicolumn{3}{|c|}{ cost scenario } & \multicolumn{3}{c|}{ cost scenario } \\
\cline { 5 - 9 } & & low & base & high & low & base & high \\
\hline B737-300 & 125 & 9.5 & 14.8 & 34.1 & 28.9 & 57.8 & 102.3 \\
\hline B737-100 & 113 & 9.2 & 11.3 & 31.6 & 32.0 & 63.3 & 111.1 \\
\hline B737-500 & 100 & 8.9 & 13.7 & 31.6 & 24.5 & 50.3 & 91.1 \\
\hline B737-800 & 174 & 7.8 & 12.5 & 33.1 & 36.5 & 71.3 & 122.6 \\
\hline B/3/-200 & 218 & 10.3 & 16.1 & $40 . /$ & 46.2 & 88.2 & $149 . /$ \\
\hline B767-300ER & 240 & 14.2 & 22.5 & 57.1 & 54.2 & 108.4 & 189.5 \\
B747 400 & 406 & 27.6 & 42.2 & 102.4 & 97.5 & 183.8 & 332.7 \\
\hline A319 & 126 & 7.1 & 11.1 & 29.1 & 28.1 & 56.4 & 101.3 \\
\hline A320 & 155 & 7.7 & 12.0 & 32.3 & 32.9 & 65.3 & 115.0 \\
\hline A321 & 166 & 9.5 & 14.9 & 36.2 & 36.5 & 70.7 & 122.2 \\
\hline ATR42 & 46 & 1.6 & 2.6 & 10.8 & 9.1 & 21.9 & 42.8 \\
\hline ATR72 & 64 & 2.2 & 3.4 & 12.8 & 12.7 & 28.1 & 52.6 \\
\hline
\end{tabular}


Since the data is in Euros, we have used the conversion rate of 1 Euros $=1 \$$ (as used by the report).

Further exploring their cost factors reveals the following costs involved:

- Fuel cost: The report provides different fuel burn rates for each aircraft type studied and for at all segments of the flights. The prices for all cost scenarios and conversion rate from Euro to Dollars are also provided. (See Table 2-12 and Annex C in [2]).

- Extra Crew cost: The report defines extra crew cost as extra cost paid in addition to the usual flight and cabin crew salaries and expenses. It may include employing additional crew (both flight and cabin crew) or incurring additional pay for regular crews due to unexpected increases in hours worked. The report does not specify exactly the methodologies used to obtain the crew cost component of the multiplier in order to preserve confidentiality of airline data. However, the report describes the factors by which they have increased the cost in different cost scenarios (refer to Table 1 of this paper).

- Maintenance cost: The maintenance cost is defined to be the cost of maintaining both the airframe and power plant of the aircraft. The additional maintenance cost incurred for a oneminute delay is stated in the report as approximately $15 \%$ of the Block Hour Direct Operating Cost (BHDOC). The proportions of how maintenance cost is divided into different segments of the flights are given in Annex $\mathbf{J}$ of [2]. BHDOC's are given in the report for low, base and high cost scenarios for the 12 different aircraft systems studied (see Table 2-11 in [2]).

- Depreciation Cost: The report assumes that there is no additional depreciation cost caused by delays. Thus, the depreciation component of total delay is taken to be zero for all segments and cost scenarios.

- Passenger Delay Cost: Passenger Delay cost (or PAX delay cost) is defined as the compensation paid by the airlines to passengers who have experienced delayed flights. Passenger Delay (in cost per passenger per minute) is given as: none for low and base cost scenarios, 0.05 for the high cost scenario for 15 minutes of delay and 0.32 , 0.40 and 0.48 for low, base and high cost scenarios respectively for 65 minutes delay.

- Other Costs: This factor is a catch-all component that attempts to includes any other cost factors mentioned in Table 1 (such as parking, airport charges, handling agent penalty, weight payload factor etc.). No specific cost factors were given in the report, except details for different Airport charges at different EU airports are provided (see Annex L in [2]).

One point worth mentioning is that the findings of the report are for EU airports only. We validate their cost factors by applying the imputed cost factors to their data. However, once we have obtained these costs factors, when applying the formulas to US data, we recognize the differences between the US and European systems. We have therefore adjusted the calculations accordingly to reflect these differences. For example, passenger compensation costs incurred to the airline in US are far lower than that of EU (due to EU Passenger Bill of Rights or PBR). Similarly, aircraft spend more time taxiing out in the US than in Europe. Also, in the US, Air Traffic Management imposes greater ground delay programs in order to assure that there is little circling at the destination airport. The EU report specifically comments on this difference noting that, on average, the amount of en route delay is greater than the amount of ground delay for European flights.

\section{Methodology}

\section{A. Regenerating the EU Model}

For our analysis, we start with an additive general model for each of the different segments paired with the different cost scenarios that include all the different cost factors. Due to the fidelity of the available US data, we divide the flight into three segments; gate, taxi and en-route (which includes both airborne and holding). For each of these segment, three cost scenarios and two range delays are provided, hence for all these 18 different cases (segments $\mathrm{x}$ cost scenarios $\mathrm{x}$ delay ranges), we have the following model:

$$
\begin{aligned}
& C_{\text {delay }}=c_{\text {fuel }} \times \text { fuel burn rate } \times \text { fuel price } \\
& +c_{\text {crew }} \times \text { crew cost } \\
& +c_{\text {maintenance }} \times \text { maintenance cost } \\
& +c_{\text {other }} \times \text { other cost } \\
& +c_{\text {pax }} \times \text { PAX delay cost } \times(\# \text { seats }) \times \text { load factor }
\end{aligned}
$$

All costs factors are in minutes. The coefficients in this cost model were determined so that one obtained a good fit with the EU data, as presented in the report. The validation was done using each of the three scenarios (low, base and high) and each of the 12 aircraft types in that report. Since fuel burn is directly applied in the formulation with no multiplier, the fuel coefficient (i.e. $c_{f u e l}$ ) is 1 for airborne and taxi segments and 0 for gate segment. . We fix the catch-all category "Other Costs" to be $1.6 \$^{1}$ and the other cost coefficient (i.e.c $c_{\text {other }}$ ) to be 0.15 for gate segment and 0 otherwise. Hence, the only two variables that we needed to determine were the coefficients for crew costs and for maintenance cost. The PAX cost coefficient (i.e. $c_{\text {pax }}$ ) is set to be 1 when we validate the EU model and 0 for US Data PAX Delay cost is provided by the EU as defined above.

${ }^{1}$ This represents the other cost of operations which is $\$ 1.87$ in 2008 Dollars(see [4]) 
Specifically, we need to determine the factors for all combinations of the two delay ranges, the three scenarios, and the three flight segments, or 18 (possibly different) sets of coefficients in all. We note, however, that we have assumed that the coefficients were independent of aircraft type.

\section{B. Modify Model for US Data}

In order to apply this model to the US data, we made the following changes that are more consistent to the US airlines.

- We used cost factors from the BTS P52 database (fuel price, crew and maintenance cost) [3].

- We used the fuel burn rate while en-route from the BTS P52 database and for taxi burn rate, we used ICAO engine emissions databank. (See [5]).

- We set the PAX delay cost coefficient to 0 , since in US; it is not incurred by the airlines.

For other delay ranges, we used the following formula: for any delay less than or equal to 15 minutes, we used 15 minutes cost factor, similarly for any delay above 65 minutes, we used the cost factor for 65 minutes and above delay. For delays between 15 and 65 minutes, we interpolate using the two data points.

For the network effect of these delays, we use the delay multipliers based on American Airlines case study (see Table 2-20 in [2] or [6]).

\section{Case Study}

Finally, as a case study, we applied our cost factors to 8 representative weather days at Philadelphia Airport (PHL) that have cancellation rates ranging as low as $1 \%$ to a very bad day where $68 \%$ of the flights were cancelled. The data is taken from ASPM database [7]. Table 5 shows the days we used with the $\%$ cancellation of flights on these days. We only use the flights data that were actually flown on these days. The choice for such days was based on fact that Ground Delay Program was employed on these days and huge delays were incurred by airlines.

TABle 5: DAys SElected FOR CASE STUdy

\begin{tabular}{|l|l|}
\hline Date & \% Cancellation of Flights \\
\hline $2 / 13 / 2007$ & $40 \%$ \\
\hline $3 / 16 / 2007$ & $68 \%$ \\
\hline $3 / 23 / 2007$ & $1 \%$ \\
\hline $8 / 9 / 2007$ & $16 \%$ \\
\hline $2 / 1 / 2008$ & $14 \%$ \\
\hline $2 / 12 / 2008$ & $14 \%$ \\
\hline $2 / 22 / 2008$ & $22 \%$ \\
\hline $6 / 23 / 2008$ & $1 \%$ \\
\hline
\end{tabular}

Our next section describes all the results and observations we found during our analysis.

\section{RESULTS}

Before beginning the work to determine the cost coefficients for the new model, we first examined whether overall cost factors in the US appear to be similar to those incurred in Europe. We computed the different types of delay cost (gate, taxi and airborne and holding,) for the given 12 aircrafts and compared it with the average operational cost per minute using P52 [3] data from the BTS database for US airlines. Figure 1, 2 and 3 show that, in all of these flight segments, the trends are similar affirming the fact that these cost factors are consistent with the operational costs in the US.

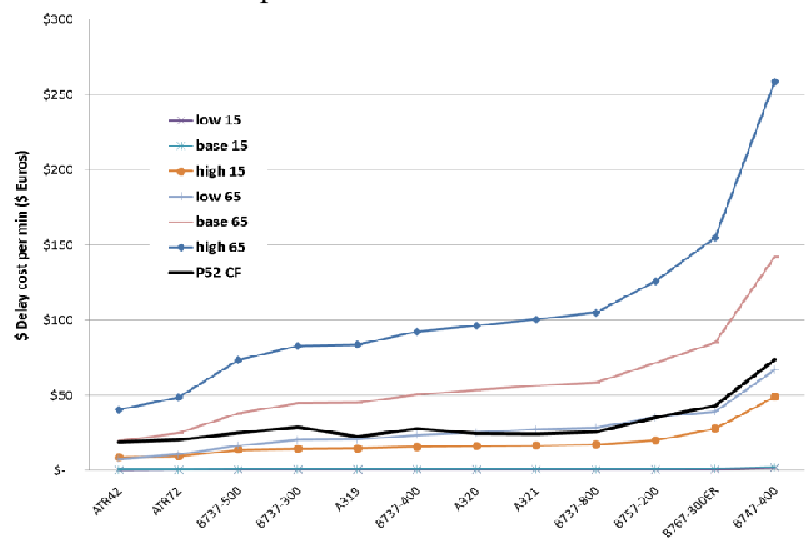

Figure 1: Tactical Ground Delay costs: gate only (without network effect) vs. Operational costs

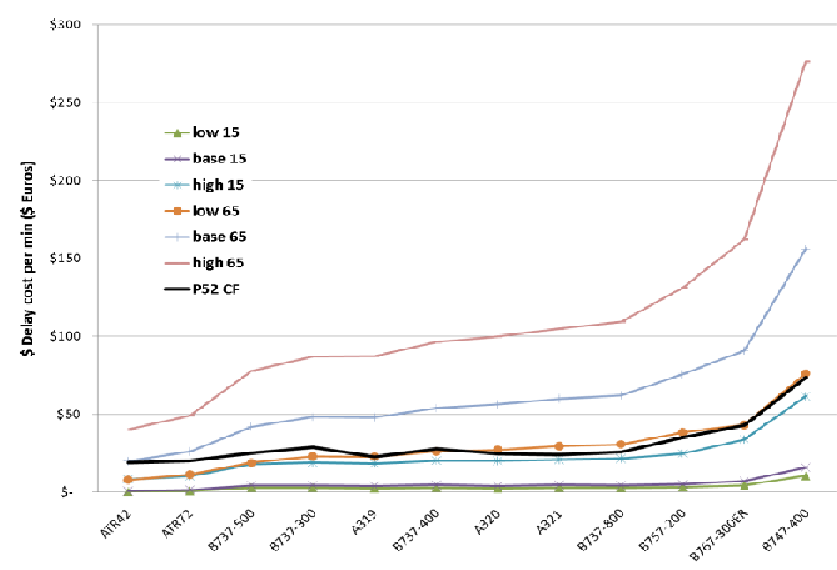

Figure 2: Tactical Ground Delay Costs: Taxi only (without network effect) vs. Operational costs 


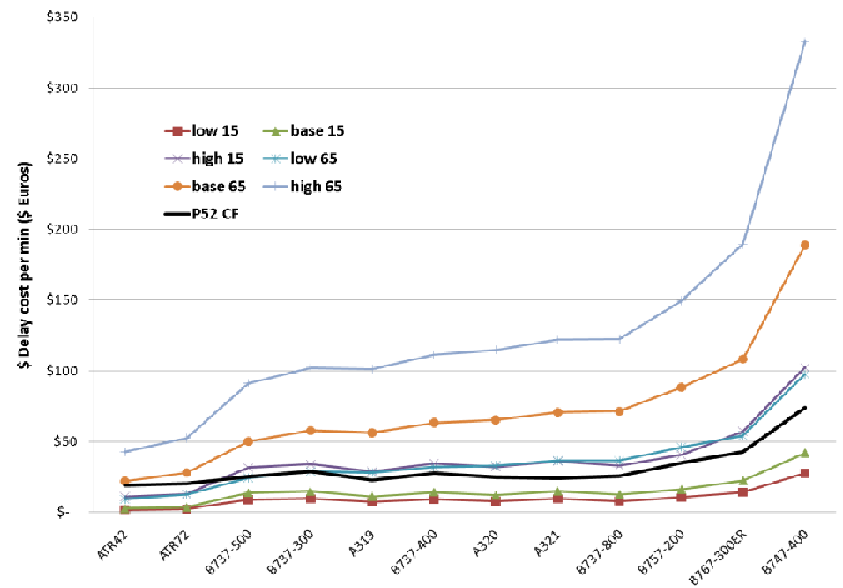

Figure 3: Tactical Airborne Delay Costs en-route and holding (without network effect) vs. Operational costs

Tables 6-8 validate our general approach by showing the percent difference between the provided EU cost factors and our computed cost factors for given 12 aircrafts. Green cells indicate the cases where EU cost factors are $10 \%$ higher than ours; Red cells indicate the cases where our cost factor is $10 \%$ higher than EU reports. All the remaining cells have values with difference of within $10 \%$. As a result of fitting the general model to the EU report delay cost factors, Table 9 provides the coefficients of involved cost factors for all different scenarios, both delay types and different segments of the flight.

TABle 6: TACTICAL GROUND Delay COSTS: GROUND ONLY. DifFERENCE BETWEEN EU AND OUR COST FACTORS FOR GIVEN 12 AIRCRAFTS (COMPARED TO TABLE 2 OF THIS PAPER)

\begin{tabular}{|c|c|c|c|c|c|c|c|}
\hline \multirow{3}{*}{\multicolumn{2}{|c|}{$\begin{array}{l}\text { Aircraft and } \\
\text { Number of seats }\end{array}$}} & \multirow{2}{*}{\multicolumn{3}{|c|}{$\frac{\text { Based on } 15 \text { min. delay }}{\text { cost scenario }}$}} & \multirow{2}{*}{\multicolumn{3}{|c|}{ Based on 65 min. delay }} \\
\hline & & & & & & & \\
\hline & & \multirow{2}{*}{ low } & \multirow{2}{*}{$\frac{\text { base }}{0.31}$} & \multirow{2}{*}{\begin{tabular}{|l|} 
high \\
0.20
\end{tabular}} & \multirow{2}{*}{ low } & \multirow{2}{*}{\begin{tabular}{|l|} 
base \\
0.08
\end{tabular}} & \multirow{2}{*}{$\begin{array}{r}\text { high } \\
0.12\end{array}$} \\
\hline ATR42 & 46 & & & & & & \\
\hline ATR72 & 64 & 0.05 & 0.14 & 0.07 & $(0.02)$ & 0.02 & 0.03 \\
\hline B737-500 & 100 & $(0.05)$ & $(0.01)$ & 0.03 & $(0.03)$ & 0.01 & 0.03 \\
\hline B737-300 & 125 & $(0.05)$ & $(0.01)$ & $(0.02)$ & $(0.03)$ & $(0.02)$ & $(0.03)$ \\
\hline A319 & 126 & 0.03 & 0.09 & (0.01) & $(0.02)$ & $(0.02)$ & (0.03) \\
\hline B737-400 & 143 & $(0.05)$ & 0.01 & $(0.01)$ & $(0.02)$ & $(0.02)$ & $(0.02)$ \\
\hline A 320 & 155 & 0.03 & 0.07 & $(0.01)$ & $(0.02)$ & 0.00 & $(0.04)$ \\
\hline A321 & 166 & 0.02 & 0.08 & $(0.04)$ & $(0.01)$ & $(0.03)$ & $(0.05)$ \\
\hline B737-800 & 174 & $(0.09)$ & $(0.03)$ & 0.01 & $(0.02)$ & 0.02 & 0.00 \\
\hline B757-200 & 218 & $(0.03)$ & 0.03 & $(0.03)$ & $(0.01)$ & $(0.02)$ & $(0.03)$ \\
\hline B767-300A & 240 & $(0.09)$ & $(0.00)$ & 0.00 & $(0.02)$ & 0.02 & $(0.02)$ \\
\hline B747-400 & 406 & $(0.12)$ & (0.10) & 0.08 & $(0.03)$ & 0.03 & 0.08 \\
\hline
\end{tabular}

TABle 7: TACTICAL GRound Delay COSTS: TAXI ONLY. DifFERENCE BETWEEN EU AND OUR COST FACTORS FOR GIVEN 12 AIRCRAFTS (COMPARED TO TABLE 3 OF THIS PAPER)

\begin{tabular}{|c|c|c|c|c|c|c|c|}
\hline \multirow{3}{*}{\multicolumn{2}{|c|}{$\begin{array}{l}\text { Aircraft and } \\
\text { Number of seats }\end{array}$}} & \multirow{2}{*}{\multicolumn{3}{|c|}{$\frac{\text { Based on } 15 \text { min. delay }}{\text { cost scenario }}$}} & \multirow{2}{*}{\multicolumn{3}{|c|}{\begin{tabular}{|c|} 
Based on 65 min. delay \\
cost scenario \\
\end{tabular}}} \\
\hline & & & & & & & \\
\hline & & \multirow{2}{*}{\begin{tabular}{|l|} 
low \\
\end{tabular}} & \multirow{2}{*}{\begin{tabular}{|r|} 
base \\
0.31
\end{tabular}} & \multirow{2}{*}{\begin{tabular}{|r|} 
high \\
0.20
\end{tabular}} & \multirow{2}{*}{\begin{tabular}{|r|} 
low \\
$(0.02)$ \\
\end{tabular}} & \multirow{2}{*}{\begin{tabular}{|r|} 
base \\
0.08 \\
\end{tabular}} & \multirow{2}{*}{\begin{tabular}{|r|} 
high \\
0.12 \\
\end{tabular}} \\
\hline \begin{tabular}{|l|} 
ATR42 \\
\end{tabular} & 46 & & & & & & \\
\hline ATR72 & 64 & 0.05 & 0.14 & 0.07 & $(0.02)$ & 0.02 & 0.03 \\
\hline B737-500 & 100 & (0.05) & $(0.01)$ & 0.03 & $(0.03)$ & 0.01 & 0.03 \\
\hline B737-300 & 125 & $(0.05)$ & $(0.01)$ & $(0.02)$ & $(0.03)$ & $(0.02)$ & $(0.03)$ \\
\hline A319 & 126 & 0.03 & 0.09 & (0.01) & $(0.02)$ & $(0.02)$ & $(0.03)$ \\
\hline B737-400 & 143 & $(0.05)$ & 0.01 & $(0.01)$ & $(0.02)$ & $(0.02)$ & $(0.02)$ \\
\hline A320 & 155 & 0.03 & 0.07 & $(0.01)$ & $(0.02)$ & 0.00 & $(0.04)$ \\
\hline$A 321$ & 166 & 0.02 & 0.08 & $(0.04)$ & $(0.01)$ & $(0.03)$ & $(0.05)$ \\
\hline B737-800 & 174 & $(0.09)$ & $(0.03)$ & 0.01 & $(0.02)$ & 0.02 & 0.00 \\
\hline B757-200 & 218 & $(0.03)$ & 0.03 & $(0.03)$ & $(0.01)$ & $(0.02)$ & $(0.03)$ \\
\hline B767-300 & 240 & $(0.09)$ & $(0.00)$ & 0.00 & $(0.02)$ & 0.02 & $(0.02)$ \\
\hline B747-400 & 406 & $(0.12)$ & $(0.10)$ & 0.08 & $(0.03)$ & 0.03 & 0.08 \\
\hline
\end{tabular}

TABle 8: TACTiCAl Airborne Delay: ENROUTE AND HOlding. DifFERENCE BETWEEN EU AND OUR COST FACTORS FOR GIVEN 12 AIRCRAFTS (COMPARED TO TABLE 4 OF THIS PAPER)

\begin{tabular}{|c|c|c|c|c|c|c|c|}
\hline \multirow{3}{*}{\multicolumn{2}{|c|}{$\begin{array}{l}\text { Aircraft and } \\
\text { Number of seats }\end{array}$}} & \multirow{2}{*}{\multicolumn{3}{|c|}{$\frac{\text { Based on } 15 \text { min. delay }}{\text { cost scenario }}$}} & \multirow{2}{*}{\multicolumn{3}{|c|}{$\frac{\text { Based on } 65 \text { min. delay }}{\text { cost scenario }}$}} \\
\hline & & & & & & & \\
\hline & & low & \multirow{2}{*}{\begin{tabular}{|r|} 
base \\
0.07 \\
\end{tabular}} & \multirow{2}{*}{\begin{tabular}{|r|}
\multicolumn{1}{|l|}{ high } \\
0.15 \\
\end{tabular}} & \multirow{2}{*}{\begin{tabular}{|r|} 
low \\
0.00 \\
\end{tabular}} & \multirow{2}{*}{\begin{tabular}{|r|} 
base \\
0.07 \\
\end{tabular}} & \multirow{2}{*}{\begin{tabular}{|r|}
\multicolumn{1}{|l|}{ high } \\
0.11 \\
\end{tabular}} \\
\hline \begin{tabular}{|l|} 
ATR42 \\
\end{tabular} & 46 & 0.08 & & & & & \\
\hline ATR72 & 64 & 0.00 & $(0.02)$ & 0.04 & $(0.00)$ & 0.02 & 0.04 \\
\hline B737-500 & 100 & 0.15 & 0.14 & 0.12 & 0.02 & 0.03 & 0.05 \\
\hline B737-300 & 125 & 0.13 & 0.13 & 0.08 & 0.01 & $(0.00)$ & 0.00 \\
\hline A319 & 126 & $(0.10)$ & $(0.11)$ & $(0.06)$ & $(0.01)$ & $(0.03)$ & $(0.02)$ \\
\hline B737-400 & 143 & 0.11 & 0.10 & 0.06 & 0.01 & $(0.00)$ & 0.00 \\
\hline A320 & 155 & $(0.04)$ & $(0.04)$ & $(0.02)$ & $(0.01)$ & $(0.00)$ & $(0.02)$ \\
\hline A321 & 166 & 0.01 & 0.01 & $(0.02)$ & $(0.00)$ & $(0.03)$ & $(0.03)$ \\
\hline \begin{tabular}{|l|} 
B737-800 \\
\end{tabular} & 174 & $(0.12)$ & $(0.09)$ & $(0.04)$ & $(0.01)$ & 0.01 & $(0.00)$ \\
\hline B757-200 & 218 & $(0.09)$ & $(0.09)$ & $(0.07)$ & $(0.01)$ & $(0.03)$ & $(0.03)$ \\
\hline B767-300日 & 240 & $(0.11)$ & $(0.11)$ & $(0.05)$ & $(0.01)$ & 0.01 & $(0.02)$ \\
\hline B747-400 & 406 & $(0.20)$ & $(0.22)$ & (0.03) & (0.02) & 0.01 & 0.08 \\
\hline
\end{tabular}

When using the same model but using fuel burn rates as reported in US databases, we observed that fuel burn rates reported in the US are lower than reported in the EU report. 
TABLE 9: COEFFICIENTS COMPUTED ON FITTING THE EU DATA

\begin{tabular}{|c|c|c|c|c|c|c|}
\hline \multicolumn{7}{|c|}{ Gate Only } \\
\hline \multirow{3}{*}{ Cost Factors } & \multicolumn{3}{|c|}{ Based on 15 Minutes Delay } & \multicolumn{3}{|c|}{ Based on 65 Minutes Delay } \\
\hline & \multicolumn{3}{|c|}{ cost scenario } & \multicolumn{3}{|c|}{ cost scenario } \\
\hline & Low & Base & High & Low & Base & High \\
\hline Fuel & 0 & 0 & 0 & 0 & 0 & 0 \\
\hline Crew & 0 & 0 & 0.5 & 0 & 0.85 & 2 \\
\hline Maintenance & 0.02 & 0.02 & 0.05 & 0.05 & 0.05 & 0.05 \\
\hline PAX delay & 1 & 1 & 1 & 1 & 1 & 1 \\
\hline Other & 0.15 & 0.15 & 0.15 & 0.15 & 0.15 & 0.15 \\
\hline \multicolumn{7}{|c|}{ Taxi Only } \\
\hline \multirow{3}{*}{ Cost Factors } & \multicolumn{3}{|c|}{ Based on 15 Minutes Delay } & \multicolumn{3}{|c|}{ Based on 65 Minutes Delay } \\
\hline & \multicolumn{3}{|c|}{ cost scenario } & \multicolumn{3}{|c|}{ cost scenario } \\
\hline & Low & Base & High & Low & Base & High \\
\hline Fuel & 1 & 1 & 1 & 1 & 1 & 1 \\
\hline Crew & 0 & 0 & 0.5 & 0 & 0.85 & 2 \\
\hline Maintenance & 0.02 & 0.02 & 0.05 & 0.05 & 0.05 & 0.05 \\
\hline PAX delay & 1 & 1 & 1 & 1 & 1 & 1 \\
\hline Other & 0 & 0 & 0 & 0 & 0 & 0 \\
\hline \multicolumn{7}{|c|}{ En-route } \\
\hline \multirow{3}{*}{ Cost Factors } & \multicolumn{3}{|c|}{ Based on 15 Minutes Delay } & \multicolumn{3}{|c|}{ Based on 65 Minutes Delay } \\
\hline & \multicolumn{3}{|c|}{ cost scenario } & \multicolumn{3}{|c|}{ cost scenario } \\
\hline & Low & Base & High & Low & Base & High \\
\hline Fuel & 1 & 1 & 1 & 1 & 1 & 1 \\
\hline Crew & 0 & 0 & 0.5 & 0 & 0.85 & 2 \\
\hline Maintenance & 0.02 & 0.02 & 0.1 & 0.05 & 0.05 & 0.1 \\
\hline PAX delay & 1 & 1 & 1 & 1 & 1 & 1 \\
\hline Other & 0 & 0 & 0 & 0 & 0 & 0 \\
\hline
\end{tabular}

This means that even using the same model, we come up with slightly lower cost factors than that of the EU report. Table 10 shows the final cost factors computed using the model with our data. We have used the coefficients for the base cost scenario.

TABle 10: OUR COEFFICIENTS FOR DIFFERENT COST FACTORS FOR US DATA

\begin{tabular}{|c|r|r|r|r|r|r|}
\hline \multirow{2}{*}{$\begin{array}{c}\text { Cost } \\
\text { Factors }\end{array}$} & \multicolumn{2}{|c|}{ Gate } & \multicolumn{2}{c|}{ Taxi } & \multicolumn{2}{c|}{ En-route } \\
\cline { 2 - 7 } & $\begin{array}{c}\mathbf{1 5} \\
\text { min }\end{array}$ & $\begin{array}{c}\mathbf{6 5} \\
\text { min }\end{array}$ & $\begin{array}{c}\mathbf{1 5} \\
\text { min }\end{array}$ & $\begin{array}{c}\mathbf{6 5} \\
\text { min }\end{array}$ & $\begin{array}{c}\mathbf{1 5} \\
\text { min }\end{array}$ & $\begin{array}{c}\mathbf{6 5} \\
\text { min }\end{array}$ \\
\hline Fuel & 0 & 0 & 1 & 1 & 1 & 1 \\
\hline Crew & 0 & 0.85 & 0 & 0.85 & 0 & 0.85 \\
\hline $\begin{array}{c}\text { Mainten } \\
\text { ance }\end{array}$ & 0.02 & 0.05 & 0.02 & 0.05 & 0.02 & 0.05 \\
\hline PAX & 0 & 0 & 0 & 0 & 0 & 0 \\
\hline Other & 0.15 & 0.15 & 0 & 0 & 0 & 0 \\
\hline
\end{tabular}

Finally, using the model and the delay multipliers from American Airlines case study (in Appendix Table 2-20 in [2]); we priced all the delayed flights on the 8 weather days at PHL. Following charts describe some of the results of this case study.

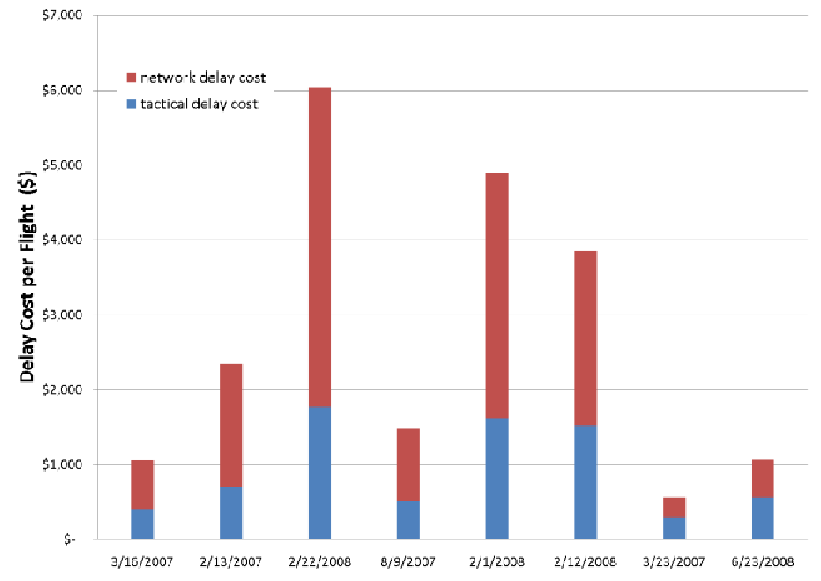

Figure 4: Total Cost of delay per observed day

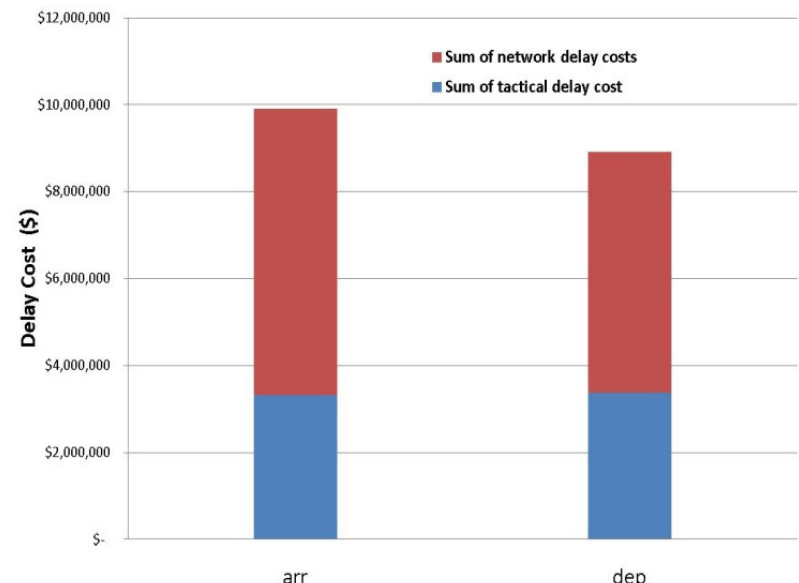

Figure 5: Delay costs (arrivals vs. departures at PHL)

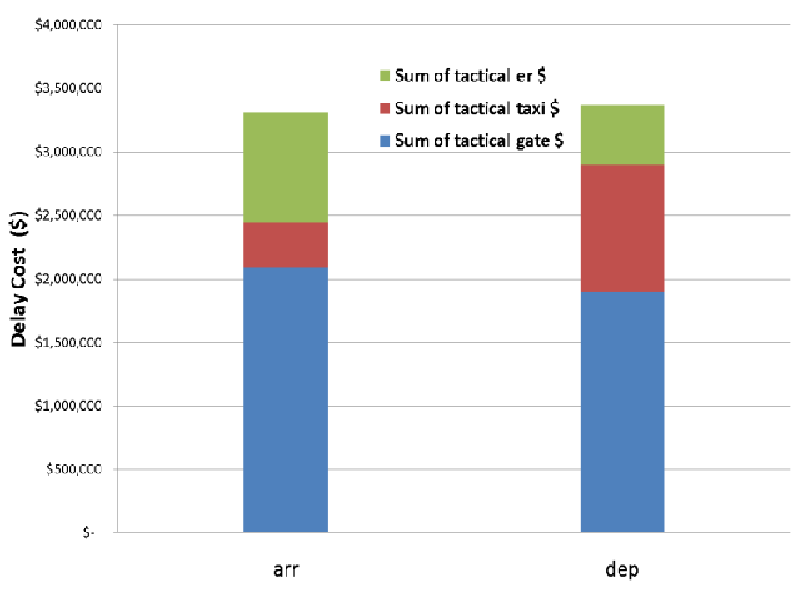

Figure 6: Arrival vs. Departure Tactical Delay costs across all segments of flight 


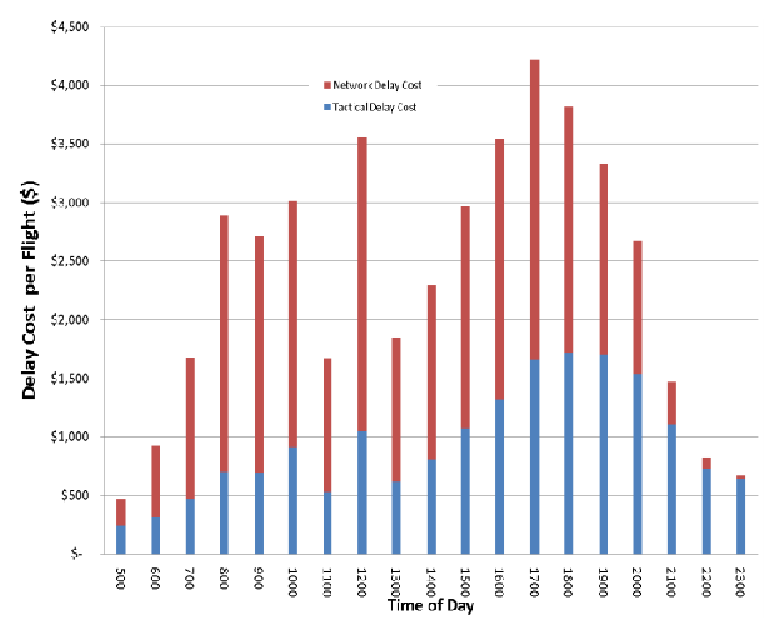

Figure 7: Departure cost of delay per flight by time of day
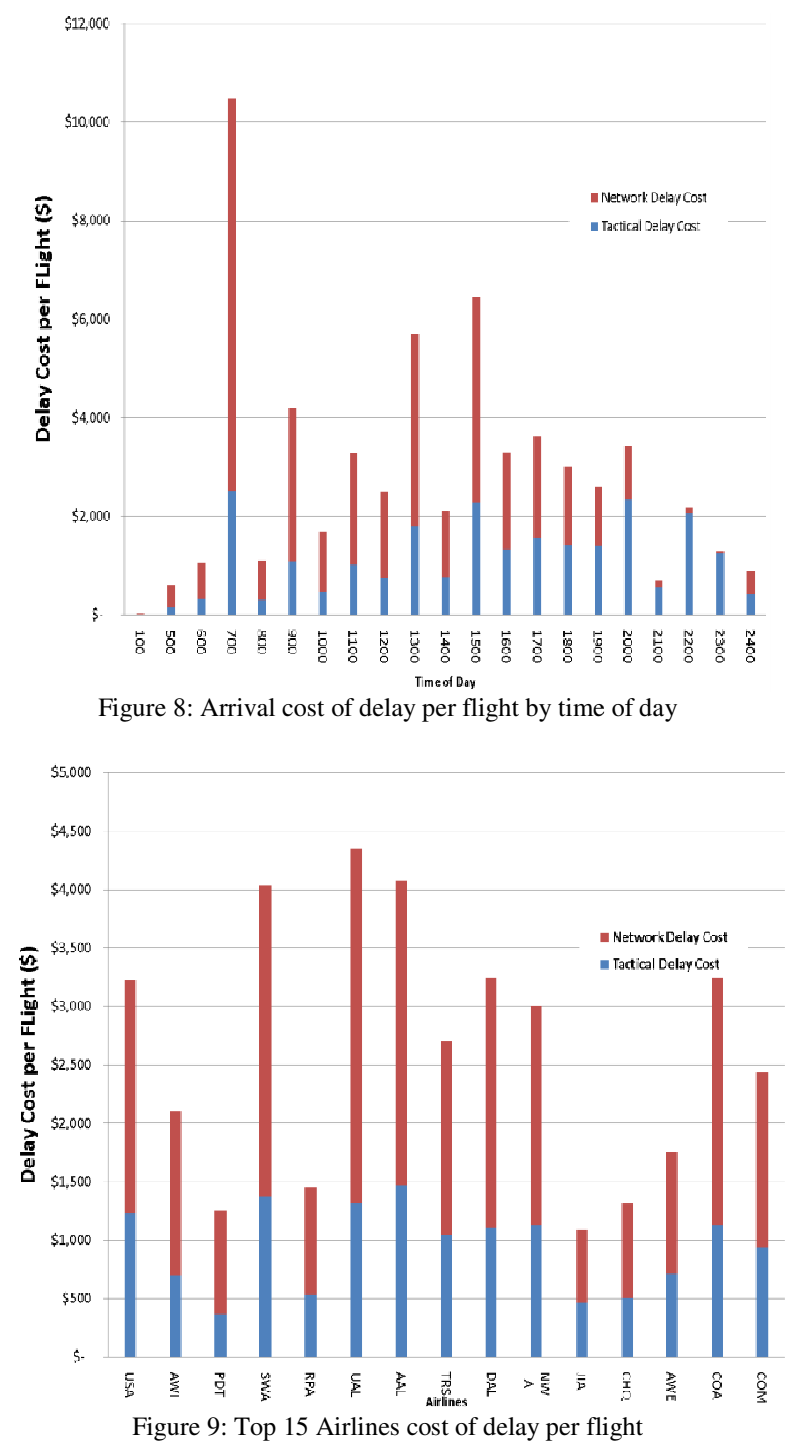

- Total cost of delay for each observed day in descending order of the $\%$ of cancelled flights (Figure 4).

- Total cost of delay for arrivals vs. departure at PHL (Figure 5).

- Total cost of primary delay for arrivals vs. departures at PHL divided into segments of flights (Figure 6).

- Departure delay of cost per flight by time of day (Figure 7).

- Arrival delay of cost per flight by time of day (Figure 8).

- Top 15 Airlines by cost of delay incurred per flight (Figure 9).

\section{CONCLUSIONS}

From our analysis, we conclude the following:

- The cost factors from the EU report follow similar trends as observed using US data. Thus, the general approach taken by the EU report can be applied, with minor modifications, to compute the cost of delays for US flights

- We determined the components of their cost model as cost factors of available data and found fairly close overall factors, thus providing us with confidence about our model.

- Looking at the cost of delay for each observed day, we found that the cost of delay is not proportional to the flights flown. For example, day " $2 / 22 / 2008$ ", despite having only $22 \%$ cancelled flight has the highest cost of delay while day "3/16/2007" with the highest number of cancelled flight has very low cost of delay. One reason for this non-intuitive result is that when a flight is cancelled, it is recorded as having zero delay. Future research will address further how to handle this anomaly in record-keeping.

- Cost of departure and arrival delays at PHL are very similar.

- Looking at the long taxi delays, it seems that US airlines (the dominant airline at PHL with nearly $80 \%$ of the flights) behaves as a Stackelberg ${ }^{2}$ leader and schedules it flights at peak times in order to restrict competition.

- We observe peaking at PHL and the overscheduling during these periods result in larger delay costs. The network delays are not necessarily larger for these peak times.

${ }^{2}$ For details on possible airline behavior interacting with other airlines, see [8] 
- One interesting result shows that not all airlines incur similar delay costs at PHL. Southwest, United Airlines, Delta Airlines and American Airlines all have higher costs of delay at PHL than does the dominant carrier, US Airways. Also, the regional airlines have lower costs of delay than the larger ones. Here too, the issue may be one of the way in which the data is recorded. The regional jets are more likely to be cancelled than the larger aircraft and, when cancelled, the data records such flights as having zero delay.

- Our calculations of the cost of delayed flights (but not cancelled flights) totals $\$ 18 \mathrm{M}$ for these 8 days.

Many modeling and analysis efforts require a good understanding of the costs that an airline will incur when it experiences delays at the gate, while taxiing or while en-route. This paper has presented a relatively straightforward mechanism for calculating such costs and for predicting how such costs are likely to increase when there is a change in fuel costs, aircraft type, or other major alternative in the cost structure. It is informative in explaining why airlines are currently down-gauging the size of the aircraft used even at airports with substantial capacity restrictions.

\section{FUTURE WORK}

We intend to both expand and apply this model in a variety of efforts currently underway:

- Firstly, we need to include the costs of cancellations into the model.

- We wish to apply the model and investigate its sensitivity to significant cost changes in fuel or crew, and changes in aircraft usage. Having a mechanism to understand costs by aircraft type allows us to use the model for aircraft not in the EU study.

- We intend to apply this model to a variety of different airports and see how airline costs vary based on different mixes of aircraft, varying amounts of airline dominance, and alternative government policies (such as slot-controls, rules about entry into the airport, etc.)

- We intend to examine if, based on these costs, we can predict which flights are most likely to be cancelled or delayed when weather conditions result in the initiation of a ground-delay program.

- Once this model has been validated for a variety of different congestion scenarios and airports, we intend to include the model as part of a larger equilibrium model that predicts the actions of airlines under various policy decisions. See [9] for more on this effort.

- We intend to use this as a tool in a congestionpricing model to determine the flights that are most likely to be cancelled first when capacity at an airport is reduced, and thereby to determine the prices that would be needed to have supply approximately equal demand if congestion pricing where imposed at some airport imposed.

\section{REFERENCES}

[1] C. E. Schumer, "Flight Delays Cost Passengers, Airlines and the U.S Economy Billions". A Report by the Joint Committee Majority Staff, May 2008

[2] Performance Review Unit, Eurocontrol, "Evaluating the True Cost to Airlines of One Minute of Airborne or Ground Delay," University of Westminster Final Report, May, 2004.

[3] (Online) Bureau of Transportation Statistics (BTS) Databases and Statistics. http://www.transtats.bts.gov/

[4] (Online) Air Transport Association of America, Inc (ATA), cost of delays. http://www.airlines.org/economics/cost+of+delays/ (2008).

[5] (Online) ICAO Engine Emissions databank, ICAO Committee on Aviation Environmental Protection (CAEP), hosted on UK Civil Aviation Authority, http://www.caa.co.uk/default.aspx?catid=702 (Updated Feb 2009).

[6] Beatty R, Hsu R, Berry L \& Rome J,"Preliminary Evaluation of Flight Delay Propagation through an Airline Schedule",2nd USA/Europe Air Traffic Management R\&D Seminar,December 1998

[7] (Online) Aviation System Performance Metrics (ASPM)-Complete FAA, http://aspm.faa.gov/aspm/entryASPM.asp

[8] J. K. Brueckner, Internalization of airport congestion: A network analysis, International Journal of Industrial Organization, Elsevier, vol. 23(7-8), pages 599-614, September 2005

[9] L. Le "Demand Management at Congested Airports: How far are we from Utopia?", PhD Dissertation, Systems Engineering and Operations Research Department, George Mason University, VA (July 2006)

APPENDIX 
TABle 11: American Airlines Case Study Delay MultiPliER (From [6])

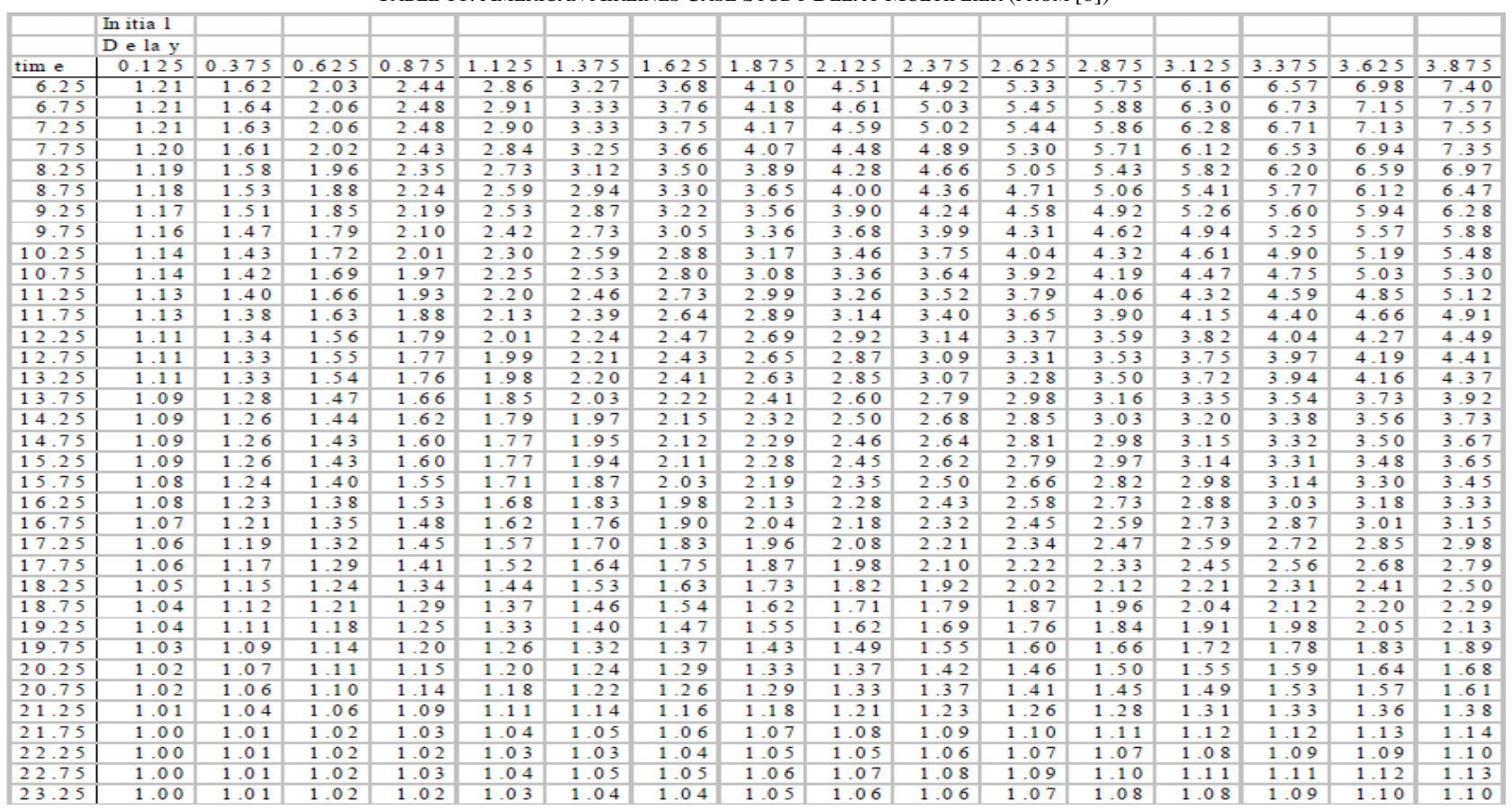

